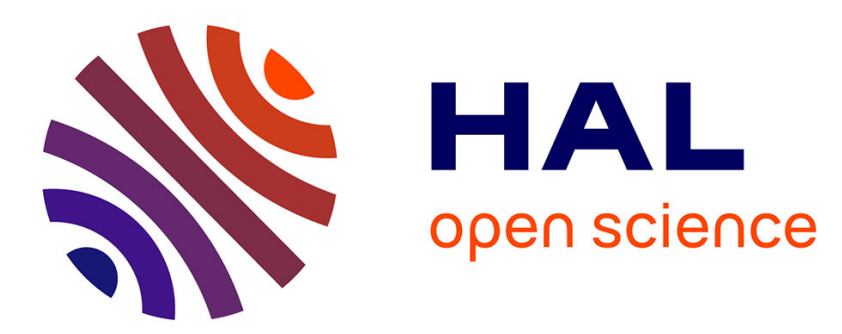

\title{
An Intelligent Web-Based Learning System for Group Collaboration Using Contracts
}

\author{
Henri Frederico Frederico Eberspächer, Michèle Joab
}

\section{To cite this version:}

Henri Frederico Frederico Eberspächer, Michèle Joab. An Intelligent Web-Based Learning System for Group Collaboration Using Contracts. ITS 2008 - 9th International Conference on Intelligent Tutoring Systems, Jun 2008, Montréal, Canada. pp.734-736, 10.1007/978-3-540-69132-7_93 . lirmm00325749

\section{HAL Id: lirmm-00325749 \\ https://hal-lirmm.ccsd.cnrs.fr/lirmm-00325749}

Submitted on 30 Sep 2008

HAL is a multi-disciplinary open access archive for the deposit and dissemination of scientific research documents, whether they are published or not. The documents may come from teaching and research institutions in France or abroad, or from public or private research centers.
L'archive ouverte pluridisciplinaire HAL, est destinée au dépôt et à la diffusion de documents scientifiques de niveau recherche, publiés ou non, émanant des établissements d'enseignement et de recherche français ou étrangers, des laboratoires publics ou privés. 


\title{
An Intelligent Web-Based Learning System for Group Collaboration Using Contracts
}

\author{
Henri Eberspächer ${ }^{1,2}$, Michelle Joab ${ }^{1}$ \\ ${ }^{1}$ LIRMM - Université Montpellier II/CNRS 161 rue Ada 34392 Montpellier, France \\ ${ }^{2}$ PUCPR - Pontifical Catholic University of Parana, Curitiba - PR, Brazil \\ Henri.Eberspacher@pucpr.br, Michelle.Joab@lirmm.fr
}

\begin{abstract}
In this paper we introduce an Intelligent Web-Based Learning System Virtus which supports role-based collaboration using a group contract model (a charter) based on roles and rules. The originality of our work consists, on the one hand, in proposing a declarative language to express contracts using declarative rules, commitments and role responsibilities and, on the other hand, in automatically executing the contract thanks to a knowledge-based system.
\end{abstract}

Keywords: Intelligent Web-based learning, Role-based collaboration, Contract.

\section{Introduction}

Web-based platforms devoted to e-learning usually provide a virtual learning environment which supports learning activities. These platforms are used within a variety of methods ranging from classroom education to partially or completely online distance education and from individual to collaborative work. They offer a wide range of tools to support one-to-one or group learning: communication tools, course management tools, content management tools and collaborative work tools .

In this paper we present a software component named VirtusCharte as a part of an e-learning platform that will support group work using a contract by automating the execution of the rules of the contract. Once the contract is defined for a group, it is translated into an executable rule language and periodically, the Virtus platform [1], resulting from our work, extracts information from the learning environment and activates a knowledge-based system for each active group in the virtual learning environment in order to ensure that the conditions described in the contract are followed.

\section{2 - Virtus platform}

The Virtus platform consists of two modules: VirtusWeb which manages the services of the learning environment (like usual Learning Management Systems) and 
VirtusCharte which implements an Intelligent Support System to support groups using the rules of the contract during collaborative work. This means that the Virtus platform supplies a regulation and monitoring mechanism [2] for group activities based on concepts of contract and role [3]. This mechanism is fully configurable through the rules expressed in the proposed contract language using freely defined roles. VirtusCharte is based primarily on an intelligent tool that will automatically support collaborative work using VirtusWeb, the LMS part of the Virtus platform. So, VirtusCharte contributes to the field of Intelligent Web-based learning.

Our proposal is based on the relation between rules and roles. Rules mean a guideline, a formula that indicates what needs to be done within a certain context. Roles mean that each person is identified with a role, so that he/she can quickly identify his/her participation, prerogatives and commitments. We use the term "role" in accordance with [4]: a role is a set of requirements that define how a member should behave in a group. The rules are based on the concepts of the learning environment: resources, activities, events and roles.

The contract declarative language is able to describe how to monitor the status of an activity and the actions carried out on an activity (such as postponing an activity deadline). Using the rules, the author of the contract expresses, for example, how to react in cases where there is a procedure that is non-compliant with the behavior expected for the role. The assigned user's roles indicate the responsibilities and expected actions of each group member. The rules could question the work carried out by other roles or those that are performed outside the specified time constraints.

Using the contract, the users will benefit from an automatic group management support mechanism. From the point of view of a human user, VirtusCharte may act as a virtual user on VirtusWeb working environment and could also recall the users' commitments by sending notifications. These actions and/or notifications are a consequence of the group contract execution.

A learning environment running on Virtus platform is made by a set of services in a given context. The context is structured on three levels: (i) the individual (private user space), (ii) the group (all group members space), and (iii) the community (whole community space). Everyone has his own private space and can participate in public spaces structured in groups within communities. An object always exists in a context and it is always handled in functional spaces categorized in services. Currently, Virtus provides three types of services: $(i)$ activity management, ( $i i)$ event management, and (iii) resource management. All functionalities take into account the three contexts (a user could participate in several groups and communities playing different roles).

As a result, we have, on the one hand, VirtusWeb an environment where activities, events and resources are created, viewed and edited, and on the other hand, VirtusCharte, a system that interacts with these objects, applying the terms of the contract. VirtusCharte must be able to consult, edit and modify them using the contract in a specific context. By separating the two software modules of the platform, we aim to run the contract mechanism independently of a particular platform. This means that VirtusCharte could, with some adaptations, be plugged in another LMS. This will be effectively applied in the system's design and in the prototype implementation.

For the development of VirtusWeb, we used free software that is commonly used in open-source LMS systems, the LAMP platform: Linux Apache, MySQL and 
PHP.VirtusCharte has been implemented in Java and uses the same classes as VirtusWeb with regard to the model of the system. We used JESS [5], a Java Expert System Shell to build the knowledge-based system used in VirtusCharte.

For each execution of the knowledge-based system in a private, community or group context, VirtusCharte built the initial facts recovering them with a selective loading algorithm importing them from the VirtusWeb database. Once it has loaded the required information, it creates its own lists of objects and deals with this information to state the necessary facts to start the expert system.

At the end of the knowledge-based system inference cycle, VirtusCharte consults the working memory (which was changed by the rules) to find the facts which indicate actions to be undertaken on the Virtus platform and notifications to be sent. The actions undertaken by the methods of VirtusCharte are performed using web services in a session where VirtusCharte becomes a user of VirtusWeb.

\section{Conclusion and further work}

The originality of our work consists in proposing a declarative language to express contracts using declarative rules, commitments and role responsibilities and in automatically executing the contract using a tailored knowledge-based system.

In the medium term, the goal is to achieve an adaptive environment in the sense that VirtusCharte will run a contract originally adopted by a group and monitor how the effective behavior of groups complies with the terms of the contract when performing a learning activity. If a discrepancy is found between the contract prescribed and the actual conduct of the group, VirtusCharte could propose changes to the contract in order to be more in line with the group behavior [6]. The contract is then re-negotiated and revised by the group members.

\section{References}

1. Eberspächer, H., Joab, M.: Virtus: group support using role-based collaboration. In: ICALT'06 - The 6th IEEE International Conference on Advanced Learning Technologies. Kerkrade, The Netherlands, pp. 1079--1081 (2006)

2. Mezura-Godoy, C., Talbot, S.: Towards Social Regulation in Computer-Supported Collaborative Work. In: CRIWG'01 - 7th International Workshop on Groupware, Darmstadt, pp. 84-89 (2001)

3. Ferraris, C., Brunier, P, Martel, C.: Constructing collaborative pedagogical situations in classrooms: a scenario and role based approach. In: CSCL'02 - Computer Support for Collaborative Learning (2002)

4. Zhu, H.: Role Mechanisms in Collaborative Systems. International Journal of Production Research, vol. 44, no. 1, pp. 181--193. Taylor \& Francis, London (2006)

5. Friedman-Hill, E.: JESS in action. Greenwich, Manning. (2003)

6. Kildare, R., Williams, R. N., Hartnett, J.: An online tool for learning collaboration and learning while collaborating. In 8th Australian Conference on Computing Education, ACM International Conference Proceeding Series, vol. 165, pp. 101--108 (2006). 